\title{
Jogos Digitais como Possibilidade para a Alfabetização Matemática: Endereçamentos da Literatura para a Prática Docente
}

\section{Digital Games as a Possibility for Mathematical Literacy: Addressing Literature for Teaching Practice}

\author{
Danielle de Sousa Silva dos Santos ${ }^{\text {ab; }}$ Luciane Ferreira Mocrosky*b; Jose de Oliveira Batista ${ }^{\mathrm{c}}$
}

\author{
${ }^{\mathrm{a} C}$ Colégio Encanto Juvenil. SP, Brasil. \\ bUniversidade Tecnológica Federal do Paraná, Programa de Pós-Graduação em Formação Científica, Educacional e Tecnológica. PR, Brasil. \\ 'Universidade Federal do Sul e Sudeste do Pará. PA, Brasil. \\ E-mail: mocrosky@gmail.com
}

\begin{abstract}
Resumo
Neste artigo apresentamos aspectos de uma pesquisa maior orientada pela interrogação "que possibilidades se abrem com os jogos digitais para a alfabetização matemática?". Conduzida segundo a abordagem fenomenológica da pesquisa qualitativa, o estudo visou inventariar trabalhos acadêmicos que tematizavam jogos e jogos digitais para a alfabetização matemática com o objetivo de compreender e explicitar elementos constitutivos para a prática pedagógica de professores alfabetizadores. O foco esteve no compartilhamento do encontrado no trajeto investigativo sobre orientações advindas da literatura que tivessem o potencial de abrir horizontes, esclarecer, familiarizar, encorajar e amparar docentes a se valerem de jogos digitais em suas ações escolares cotidianas Ao todo foram analisados trinta e um textos, dos quais foram destacadas cento e cinquenta e duas unidades significativas ao perguntado, confluindo para vinte e duas Ideias Nucleares, que desaguaram em três categorias estruturantes do fenômeno jogos-digitais- para-a-alfabetização-matemática, a saber: Postura Estudantil, Conhecimento Matemático e Aspectos Didático-pedagógicos. Destas, trouxemos neste artigo a discussão da categoria Aspectos Didático-pedagógicos, pautada no que literatura revela, evidenciando orientações pedagógicas que contemplam critérios técnicos para seleção de jogos digitais, bem como elementos pedagógicos que se dirigem ao fazer docente. Todas as orientações são anunciadas em forma de perguntas que visam fomentar a prática alfabetizadora, ou seja, o objetivo esteve em expor um roteiro para o professor fazer escolhas e organizar o ensino nos anos iniciais, tendo por fio condutor os jogos digitais para a alfabetização.
\end{abstract}

Palavras-chave: Educação Matemática. Formação de Professores. Alfabetização Matemática. Aspectos Didático-Pedagógico. Jogos Digitais.

\begin{abstract}
In this article we present aspects of a larger research guided by the question "what possibilities are open with digital games for mathematical literacy?". Conducted according to the phenomenological approach of qualitative research, the study aimed to inventory academic works that thematized digital games and games for mathematical literacy in order to understand and explain constitutive elements for the pedagogical practice of literacy teachers. The focus was on sharing what was found in the investigative path about orientations from the literature that had the potential to open horizons, clarify, familiarize, encourage and support teachers to use digital games in their daily school actions Altogether, 31 texts were analyzed, of which 152 units were highlighted significant to the question, converging to 22 Nuclear Ideas that flowed into 3 structuring categories of the phenomenon games-digital-for-literacy-mathematics, namely: Student Posture, Mathematical Knowledge and Didactic-pedagogical aspects. Of these, we bring in this article the discussion of the Didactic-pedagogical Aspects category, based on what literature reveals, showing pedagogical guidelines that include technical criteria for the selection of digital games, as well as pedagogical elements that are directed when teaching. All guidelines are announced in the form of questions aimed at promoting literacy practice, that is, the objective was to expose a script for the teacher to make choices and organize teaching in the early years, with digital games for literacy as the guiding thread.
\end{abstract}

Keywords: Mathematical Education. Teachers Formation. Mathematical Literacy. Didactic-Pedagogical Aspects. Digital Games.

\section{Introdução}

Nosso interesse pela formação de professores que ensinam matemática nos anos iniciais do ensino fundamental tem movido estudos no Grupo de Estudos Grupo de estudos e pesquisa em formação de professores (GEForProf). Dadas as experiências vividas na docência e em estudos acadêmicos, temos nos envolvido com possibilidades das Tecnologias Digitais (TD) no ensino da matemática. Frente a isso, a pergunta "como ensinar matemática a alunos que a cada ano chegam à escola com vivências tecnológicas diversas?! se mostrou nas discussões.
Com tal questionamento latente no pensar sobre o ensino, em como ensinar tais alunos, o filtro que se mostrou dentro desse caminhar foi a Alfabetização Matemática (AM). Desse modo, como alfabetizar matematicamente crianças que talvez tenham maior familiaridade com as tecnologias digitais? Com esse foco, voltamos o olhar ao pensar em modos de favorecer a formação docente para a AM, no enlace de possibilidades tecnológicas formativas para professores e, consequentemente, para alunos. Mas, afinal, o que compreendemos por AM? Com Danyluk (2010) entendemos que a alfabetização vai além da leitura de um texto. 
$\mathrm{O}$ ato de alfabetizar diz respeito à compreensão e à interpretação dos sinais, com significados, impressos em um texto, bem como a expressão escrita desses significados. Ser alfabetizado, então, é entender o que se lê e escrever o que se entende a respeito das primeiras noções das ciências (Danyluk, 2010, p.29).

Destaca-se, assim, modos de pensar e interpretar o mundo, bem como se compreender pertencente a ele. Assim, AM lança mão de elementos constitutivos da ciência, que vão ganhando formas escolares privilegiadas pela ação genuína do pensar de cada um. Ao considerar estilos de aprendizagem, se vale da matemática escolar como uma manifestação segunda do conhecimento - como diz Merleau-Ponty (1984), "uma segunda linguagem do mundo", que vai fazendo sentido por se sustentar na experiência vivida. Assim, considera-se que a AM é uma ação contínua que avança pelos sentidos que vão se fazendo para a pessoa em formação. Ação que traz consigo o alfabeto significando:

Disposição dentro de uma determinada ordem convencional das letras de uma língua. São também as primeiras noções de qualquer ciência ou, ainda, qualquer série convencional. Pode-se dizer que existem diferentes alfabetos, os quais podem ser representados através de sinais gráficos e mostrados pela linguagem peculiar a cada ciência (Danyluk, 2010, p.29).

No exposto pela pesquisadora, "alfabeto" passa a abarcar também outros símbolos e não apenas os que constituem o sistema linguístico da língua materna. Decifrar certos códigos (símbolos) formais escolares ou socialmente produzidos é uma tarefa da alfabetização, mas que não a resume a ela. É preciso interpretar o lido, comunicar o compreendido em sistemas próprios de escrita e dialogar sobre o visto num enlace da subjetividade-intersubjetividade-objetividade. Assim, na matemática, a alfabetização supera, portanto, a visão pragmática de que o Ensino Fundamental (EF) tem no domínio do algoritmo e das operações básicas sua função primordial.

Partindo do questionamento "como alfabetizar matematicamente crianças que talvez tenham maior familiaridade com as tecnologias digitais?", uma vez que os jogos como metodologia de ensino na alfabetização são bastante explorados em sala de aula, pensamos em olhar para o Jogo Digital (JD) como um recurso digital. Com esse entendimento, a possibilidade de participação dos JD na AM foi ganhando relevo, solicitando estudos mais enfáticos, que, no âmago da atuação do GEForProf, intenciona situar o professor no centro do estudo, pelo interesse de contribuir com seu fazer pedagógico, na perspectiva da AM, conforme preconizado por Daniluk (2010).

Nesta pesquisa, a meta foi estudar a produção do conhecimento socializado no cenário brasileiro, explicitando um arrazoado teórico, embasado na metacompreensão da literatura, de modo a endereçar ao professor alfabetizador elementos nucleares para organizar sua prática pedagógica. Portanto, este estudo, orientado pela interrogação "que possibilidades se abrem com os jogos digitais para a alfabetização matemática?" não visou indicar caminhos para programar, elaborar jogos ou desenvolver um produto tecnológico, mas estudar, compartilhando o encontrado no trajeto investigativo sobre orientações advindas da literatura que tivessem o potencial de abrir horizontes, esclarecer, familiarizar, encorajar e amparar docentes a se valerem de JD em suas ações escolares cotidianas.

\section{O Jogo como Atividade Humana: o que Está em Jogo?}

Muitas vezes, quando se fala em jogo, ficam em destaque aspectos a ele relacionados, como a brincadeira, a diversão, o entusiasmo, a imaginação, o relacionamento interpessoal e vários outros adjetivos favoráveis a uma ação prazerosa e de entretenimento. Refere-se, portanto, ao modo de sentir do ser humano. Quanto a isso, Huizinga (2019) diz que "o jogo é mais do que um fenômeno fisiológico ou um reflexo psicológico. Ultrapassa os limites da atividade puramente física ou biológica. É uma função significante" (Huizinga, 2019, online). Isso quer dizer que no jogo sempre há algoem-jogo, há significados subjacentes que podem levar em consideração o quanto cada indivíduo está envolvido na trama proposta, no desejo de vencer e de superar os obstáculos.

Ao trazer concepções de Huizinga (2019) para este estudo, o intuito foi explicitar o envolvimento-do-ser-paracom-o-jogo. Para o autor, é preciso questionar o porquê dos jogos e seus objetivos, em vista do mostrar-se em si, levando em consideração o que ele significa para quem o joga. São movimentos que se apresentam como o estar-nojogo, perceber-se-no-jogo e interagir-para/com-o-jogo. Essa concepção de jogo para o autor é uma

[...] atividade voluntária. Sujeito a ordens, deixa de ser jogo, podendo no máximo ser uma imitação forçada. Basta esta característica de liberdade para afastá-lo definitivamente do curso da evolução natural. [posto que] As crianças e os animais brincam porque gostam de brincar e é precisamente em tal fato que reside sua liberdade (Huizinga, 2019, online).

O jogo como atividade humana não pode ser sujeito a ordens se instalado por uma obrigação. Precisa ser voluntário e acontecer de forma livre e harmônica. O "jogo lança sobre nós um feitiço: é 'fascinante', 'cativante'. Está cheio das duas qualidades mais nobres que somos capazes de ver nas coisas: o ritmo e a harmonia" (Huizinga, 2019, online). Em Gadamer (1999, p.174) também encontramos argumentos para tais afirmações

O jogo consiste sempre em abordar uma finalidade sem fim: como uma flor que desabrocha sem razão de ser, o jogo é em si mesmo apenas enquanto se joga por jogar, ou seja, enquanto se manifesta na forma de uma atividade recreativa. É justamente nessa relação de ser própria com o que é sério, nesse "sem para que" que o jogo encontra sua finalidade.

Para o contexto descrito, em que não cabe obrigatoriedade e sim a natureza dos acontecimentos, Huizinga (2019) articula sobre as características principais do jogo, sendo elas: $\mathrm{O}$ fato 
de o jogo ser livre, de ser ele próprio liberdade; O jogo não é "vida corrente" nem "vida real'; cria ordem e é ordem; promove separação espacial em relação a vida cotidiana.

Estas características percorrem os jogos e direcionam o olhar para o quê de importante deve ser visto, o foco que rodeia a intencionalidade: eu-no-divertimento-com-o-jogo. Para a primeira característica tem-se o sentido da liberdade, não podendo ultrapassar o limite do jogar-por-prazer.

A segunda característica carrega o sentido do 'faz de conta' e 'só brincando' das crianças. Para uma melhor articulação sobre essas expressões, Huizinga (2019) coloca o exemplo de uma história contada pelo pai de uma criança: O pai foi encontrar seu filhinho de quatro anos brincando de trenzinho na frente de uma fila de cadeiras. Quando foi beijá-lo, disselhe o menino: Não dê beijo na máquina, Papai, senão os carros não vão acreditar que é de verdade (Huizinga, 2019, online).

Nota-se com o exemplo que "está enraizado profundamente na criança essa consciência do 'faz de conta'. A imaginação transcende os aspectos reais, é uma evasão da vida real para uma esfera temporária de atividade com orientação própria" (Huizinga, 2019, online).

A terceira característica está relacionada a uma visão perfeita de jogo ser quebrada. Isso quer dizer que no mero divertimento, a desobediência da ordem, das regras que o movimenta, pode afastá-lo de seu caráter próprio de jogo e de envolver jogadores respeitosos e comprometidos com acordos previamente firmados.

A última característica traz à tona o olhar para o espaço do jogo, onde tudo acontece. É o momento em que o cotidiano se ausenta e se constrói um novo ambiente, às vezes paralelo, às vezes com intersecções, mas sempre em horizontes distintos. "É-lhe reservado, quer material ou idealmente, um espaço fechado, isolado do ambiente quotidiano, e é dentro desse espaço que o jogo se processa e que suas regras têm validade" (Huizinga, 2019, online).

Os lances que possibilitam promover discussões amplas e gerais a respeito do jogo como uma atividade humana mostram-se complexos, tendo em vista que

O jogo é uma função da vida, mas não é passível de definição exata em termos lógicos, biológicos ou estéticos. $\mathrm{O}$ conceito de jogo deve permanecer distinto de todas as outras formas de pensamento através das quais exprimimos a estrutura da vida espiritual e social (Huizinga, 2019, online).

Compreendemos, com as características abordadas por Huizinga (2019) um largo espectro sobre o valor do jogo como função social. Nesse sentido, entendemos sua validade como mola propulsora para o ensino, ao situar alunos como potenciais jogadores que, ao mobilizarem conhecimentos no campo emocional e social, podem enlaçar ideias, que na alfabetização vão revelando modos de as ciências se organizarem em conteúdo de ensino.

\section{Jogos Digitais: Algumas Compreensões}

Os

JD vêm na esteira dos

analógicos
Estes são entendidos como porta de entrada nas escolas, por serem uma manifestação concreta, palpável e precursora daqueles que se valem dos aspectos tecnológicos da informática para se fazer presença. Ambos têm por fio condutor as características elencadas por Huizinga (2019), por estas se mostrarem para o jogador como algo enraizado no ato de jogar. No anseio de definir JD, visitamos autores que se lançaram a essa tarefa e encontramos em Salen e Zimmerman (2004) modos de compreender assumidos em nossos estudos:

Um sistema em que os jogadores se envolvem em um conflito artificial, definido por regras, que resulta em um produto quantificado. Os elementos chave desta definição são o fato de um jogo ser um sistema, jogadores interagem com o sistema, o jogo é uma instância de conflito, o conflito nos jogos é artificial, regras limitam o comportamento do jogador e definem o jogo, e todo jogo possui um resultado quantificável ou objetivo (Salen \& Zimmerman, 2004, p.83).

Os JD, também conhecidos por games, jogos computacionais, jogos eletrônicos, jogos virtuais e, em alguns contextos, softwares, são "desenvolvidos através de programação de computador, com interface interativa, voltada para ações de um ou mais usuários em diversos tipos de suporte" (Sousa, 2015, p.31). Na trilha de dizer sobre os JD na utilização em sala de aula, tendo por suporte autores que estudam o tema, compreendemos que esses podem ser classificados como Objetos de Aprendizagem (OA). Em pesquisa sobre os OA, Balbino (2015) expõe o Plano Nacional do Livro Didático (PNLD), classificando-os como conteúdos multimídia apresentados nas modalidades de jogos eletrônicos, simuladores, vídeos ou infográficos, e que podem ser chamados de Objetos Educacionais Digitais (OED). Assim, entendemos que os JD educacionais podem ser classificados como OED.

Outro autor que também se lança a estudar sobre o tema é o norte americano Marc Prensky, em sua obra intitulada “Aprendizagem baseada em jogos digitais' em que afirma:

A aprendizagem baseada em jogos digitais está de acordo com as necessidades e os estilos de aprendizagem da geração atual e das futuras gerações; A aprendizagem baseada em jogos digitais motiva porque é dividida; A aprendizagem baseada em jogos digitais é incrivelmente versátil, possível de ser adaptada a quase todas as disciplinas, informações ou habilidades a serem aprendidas e, quando usada de forma correta, é extremamente eficaz (Prensky, 2012, p.23).

$\mathrm{O}$ fato de os JD pertencerem à geração atual de alunos nos faz perguntar sobre o motivo, em alguns casos, pelo qual estes não vêm sendo utilizados em sala de aula. Uma possível resposta para essa lacuna, dentro da perspectiva das inquietações iniciais desta pesquisa, é a ideia de que o professor que ensina essa geração atual de alunos teve sua trajetória escolar pautada em outros meios metodológicos, os quais estão internamente ligados à forma que ensina.

Prensky (2012), ao pensar na aprendizagem baseada em JD, destaca dois aspectos: envolvimento e aprendizagem. Assim, traça dois esquemas (Figura 1) que ajudam a promover o entendimento. 
Figura 1 - Esquemas sobre aprendizagem baseada em JD

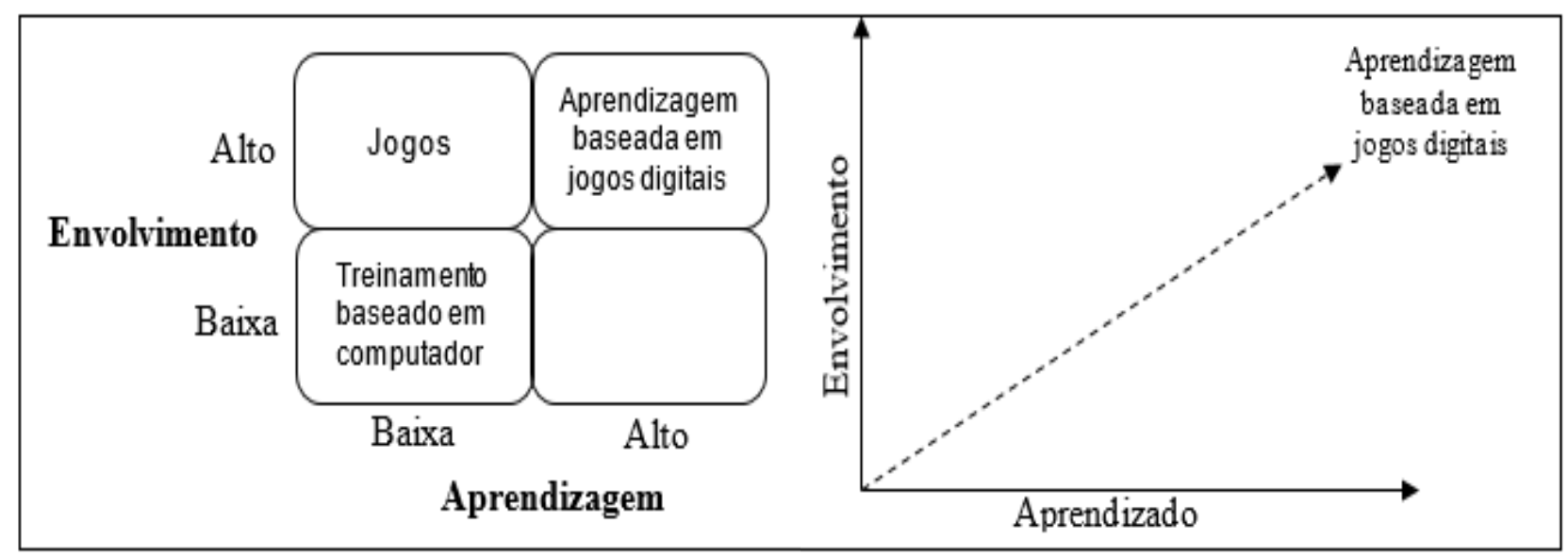

Fonte: Prensky (2012, p.212).

Para o autor, o treinamento baseado em computador tem baixo envolvimento e baixo aprendizado; o jogo analógico, no entanto, tem forte envolvimento, mas baixo aprendizado; e, por fim, os JD possuem alto envolvimento e alto aprendizado. A aprendizagem baseada em JD pode carregar variações, pois "cada dimensão é um continuum, e cada projeto tem uma quantidade diferente tanto de aprendizagem quanto de envolvimento" (Prensky, 2012, p. 213). Nesse caso, é improvável que haja um movimento contínuo que faça o balanceamento entre envolvimento e aprendizagem.

A aprendizagem baseada em jogos digitais só ocorre quando tanto o envolvimento quanto a aprendizagem são altos [...]. Uma boa aprendizagem baseada em jogos digitais não favorece nem o envolvimento nem a aprendizagem, mas luta para manter ambos em um nível alto (Prensky, 2012, p. 213).

$\mathrm{Na}$ aprendizagem baseada em JD, tal como explicitada por Prensky (2012), podemos destacar, nas entrelinhas, uma aprendizagem disfarçada . Em outras palavras, o aprender brincando se mostra. A interação do jogador com o jogo digital pode, muitas vezes, driblar a conjectura de 'pesado' que a aprendizagem carrega, visto que "aprender é um grande trabalho, não há método que funcione por si só para tudo" (Prensky, 2012, p. 27).

O trabalho, o peso e a carga do aprender são tidos por muitos, como a maior dificuldade da escola. "Aprender, como sabem os grandes professores de todas as gerações, não parece um trabalho pesado quando há alguma diversão durante o processo [...] e a aprendizagem baseada em jogos digitais pode, com certeza, ser uma diversão pesada" (Prensky, 2012, p.41). Ainda sobre o aspecto do divertimento, Para Sousa (2015), os JD têm vantagens em relação aos outros, "pois novos desafios são lançados sempre, enriquecendo a experiência do jogador no ambiente" (Sousa, 2015, p. 137). Além disso,

A habilidade de jogos de computador aprimora outras habilidades de pensamento - o que acontece de forma espontânea -, como a habilidade de fazer dobraduras mentalmente (isto é, imaginar o resultado de várias dobraduras com origami sem ter necessariamente de fazê-las) (Prensky, 2012, p.73).

Percebemos com tais discussões sobre a aprendizagem baseada em JD que há possibilidades para favorecer o processo de ensino, principalmente nos aspectos didáticometodológicos. E é em busca dessa concepção que nos debruçamos neste trabalho em busca de possibilidades para alfabetizar matematicamente com os JD.

\section{A Busca Pelas Possibilidades}

Neste estudo, orientado pela interrogação 'que possibilidades se abrem com os jogos digitais para a alfabetização matemática?' caminhamos em busca de compreensões que visassem fomentar o trabalho do professor alfabetizador matemático na escolha, análise e desenvolvimento de ações pedagógicas com JD.

A pesquisa iniciou com um inventário de trabalhos que tematizam jogos e JD na Educação Matemática (EM). Foi uma busca na literatura que visou responder: o que o professor pode olhar nesses jogos? Optou-se em procurar produções, compreendidasentre2009a2019 deprogramasdepós-graduação

stricto sensu, acadêmicos e profissionais, de Instituições de Ensino Superior (IES) públicas que apresentassem nota na Coordenação de Aperfeiçoamento de Pessoal de Nível Superior (Capes) maior ou igual a quatro.

Produções em periódicos acadêmicos Qualis-Capes A1 e A2 compreendidas entre 2015 a 2019. E artigos dos anais do Encontro Nacional de Educação Matemática (ENEM) das 5 últimas edições (compreendidos até junho de 2019). O ENEM foi escolhido por ser um evento que congrega segmentos envolvidos com a EM e com participação de professores da Educação Básica (EB), bem como de professores e estudantes das licenciaturas em matemática e pedagogia, estudantes da pós-graduação e pesquisadores. Segue, na Figura 2, o fluxograma para uma melhor visualização do detalhamento realizado nas buscas pelas produções. 
Figura 2 - Modo de busca pelas produções acadêmicas para o estudo

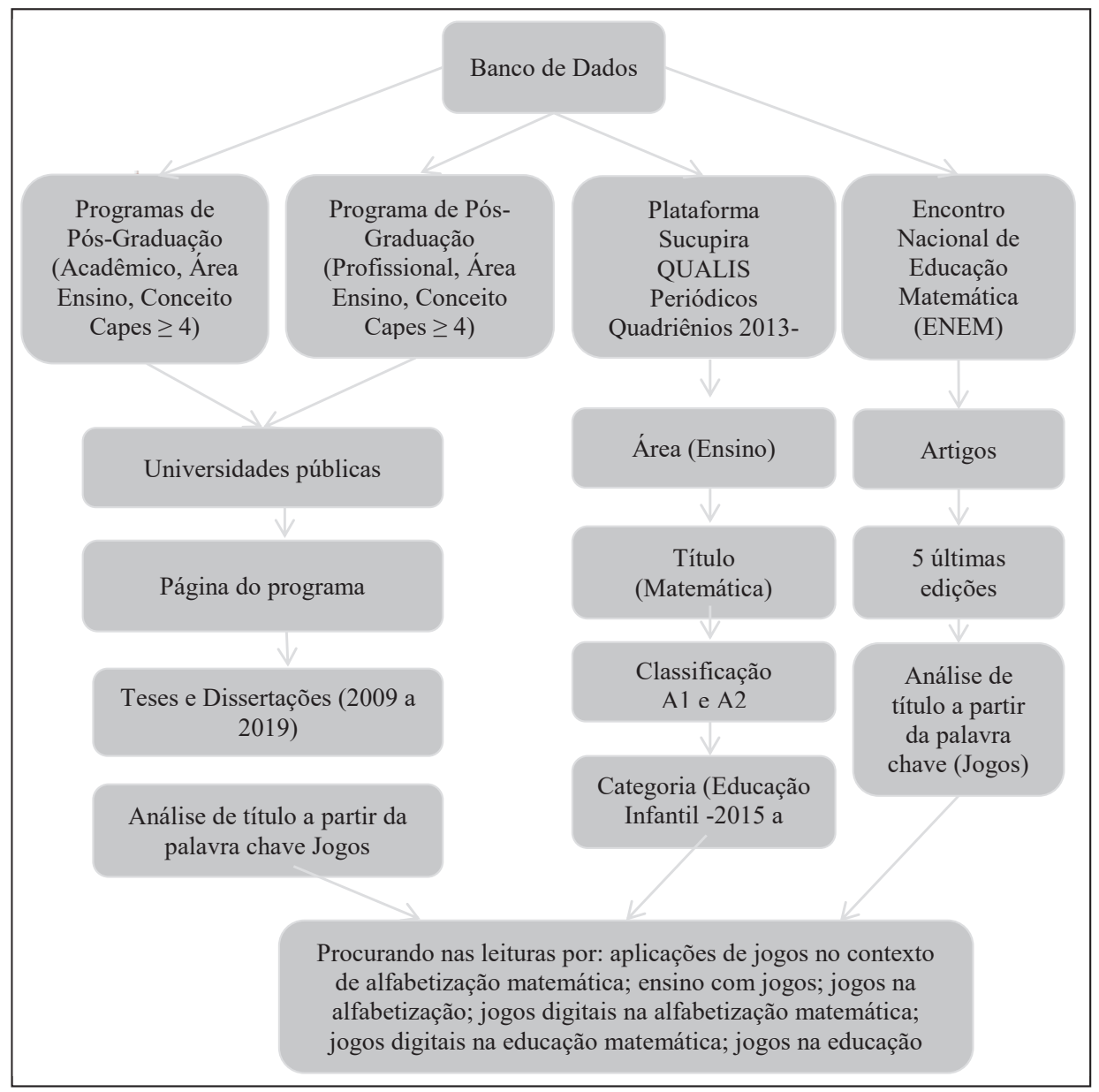

Fonte: Dados da pesquisa.

Após selecionadas, a partir das palavras-chave, as produções encontradas passaram pelo primeiro processo de análise: o critério de leitura dos resumos. Nas leituras, foram destacados os trabalhos que abordavam aplicações de JD em sala de aula em nível de Educação Infantil e EF (anos iniciais), ou concepções de professores sobre a utilização de jogos em sala de aula.

Quadro 1 - Número de trabalhos analisados

\begin{tabular}{|c|c|c|c|}
\hline & $\begin{array}{c}\text { Anais de } \\
\text { evento } \\
\text { (ENEM) }\end{array}$ & $\begin{array}{c}\text { Artigos } \\
\text { A1 e A2 }\end{array}$ & $\begin{array}{c}\text { Teses e } \\
\text { dissertações }\end{array}$ \\
\hline $\begin{array}{c}\mathrm{N}^{\circ} \text { de trabalhos } \\
\text { analisados }\end{array}$ & 24 & 5 & 2 \\
\hline $\begin{array}{c}\mathrm{N}^{\circ} \text { total de trabalhos } \\
\text { analisados }\end{array}$ & 31 & & \\
\hline
\end{tabular}

Fonte: Dados da pesquisa.

A análise dos trabalhos selecionados marca a segunda etapa da pesquisa, caracterizada pela leitura dos textos à luz da interrogação primeira. Em cada texto foram destacados trechos que respondiam à pergunta, chamados de Unidades de Significado (US), marcando o início da análise ideográfica, ou seja, dos aspectos individuais do estudo. Em seguida, todas as US são interpretadas e "transcritas para a linguagem do pesquisador, num discurso mais próprio da área na qual a pesquisa se insere" (Garnica, 1997, p. 117), tendo por solo a literatura. Dentre as 152 US deste texto, são destacadas as 22 Ideias Nucleares (IN), concentradas no núcleo das falas.

$\mathrm{O}$ trabalho, neste momento, se dirige para a passagem do individual ao geral, ou seja, para a análise nomotética, "feita com base na análise das divergências e convergências expressas pelas unidades de significado, estando vinculada, ainda, a interpretações que o pesquisador faz para obter cada uma dessas convergências, divergências ou idiossincrasias entre as IN" (Garnica, 1997, p. 117). Apontam elementos balizadores para seleção e análise de jogos alfabetizadores, anunciados pelas Categorias Abertas (CA).

As 22 IN convergiram para três CA "conhecimento matemático", "postura estudantil" e "aspectos didáticopedagógico". Este artigo visa, explicitar o que a categoria “aspectos didático-pedagógico" endereça ao fazer docente.

\section{Aspectos Didatíco-Pedagógicos: uma Categoria Emergente do Estudo}

Dentre as 22 IN evidenciadas nas 152 US, no estudo realizado, 10 delas destacaram "aspectos didáticopedagógico" como uma face do fenômeno jogos-digitais-para- 
alfabetização-matemática, por apontarem a perspectiva do professor no processo de AM com JD. De certo modo, a CA é tão ampla que congrega "atitude estudantil" e "conhecimento matemático", outras perspectivas evidenciadas no estudo maior, oportunizando pensar em como esse professor que alfabetiza matematicamente pode fazer uso dos JD como estratégia para alfabetização.

A meta é contribuir com a formação do professor a partir dos critérios pedagógicos de análise de JD evidenciados na literatura. O professor, ao entrar em contato com o jogo digital, percebe-se em um ambiente que traz aspectos tecnológicos, talvez ainda desconhecidos. As tecnologias atuais, principalmente as digitais, crescem em forte proporção e ocasionam estranhezas no modo de ser professor-comtecnologia.

O professor e o seu conhecimento - matemático, pedagógico e tecnológico — é sem dúvida, o mais importante, na medida em que é ele quem avalia e escolhe os recursos, os transforma e reinventa na sua prática na sala de aula. São os professores que selecionam os problemas, as tarefas e o método de ensino e gerenciam o desenrolar da aula, criando oportunidades significativas de aprendizagem e favorecendo o desenvolvimento de capacidades. Portanto, olhamos para o professor não apenas como o utilizador sobre o qual recai a oferta de novos produtos e aplicações, mas como aquele cujo conhecimento profissional se desenvolve e enriquece no processo de transformar recursos tecnológicos em ferramentas pedagógicas; o professor é ele mesmo um recurso imprescindível no contexto das práticas educacionais tecnologicamente enriquecidas (Amado \& Carreira, 2015, p.12).

Nas falas dos autores, encontramos o professor no centro do envolvimento entre os recursos tecnológicos e os aspectos pedagógicos, os quais se materializam no ato de ensinar. Os JD são recursos tecnológicos digitais que estão aí para serem vistos. A escolha deles para as possibilidades na AM se sustentam no ensino com TD.

Os professores e alunos de hoje pertencem a mundos totalmente diferentes. A maior dinâmica na qual se baseiam o treinamento e a aprendizagem de hoje é o choque turbulento e abrupto entre um corpo de professores criados em uma geração pré-digital, educados no estilo do passado, e um grupo de aprendizes criados no mundo digital (Prensky, 2012, p.33).

Mesmo com a diferença apontada por Prensky (2012) entre professor e aluno no habitar das TD, outros meios de trabalhar com esses alunos se mostram aos professores. Neste trabalho, tais meios são interpretados não como uma formação tecnológica que visa ensinar professores a trabalhar com recursos tecnológicos digitais, mas como um olhar pedagógico do professor para os JD como auxiliadores no processo de AM. Nesta perspectiva, destacamos trechos da análise da literatura que direcionam o olhar para os JD dentro da perspectiva dos aspectos didático-pedagógico. Assim, os jogos possibilitam:
Figura 3 - Encontro de fala dos autores estudados

[...] alternativa que fortalece e enriquece o ato pedagógico no que diz respeito ao processo de ensino aprendizagem em matemática (ALVES; LEMOS 2016, p. 2)

O professor consegue detectar os alunos que estão com dificuldades reais (PONTES; BEZERRA; BANDEIRA, 2010, p. 4)

[...] uma abordagem significativa para o trabalho com a matemática na fase inicial da escolarização, fase em que a criança necessita explora, descobrir inúmeras coisas sobre o mundo que a cerca (PAVANELLO; CAWAHISA, 2007, p. 3)

[...] favorecer a verificação de hipóteses e conjecturas levantadas pelos alunos de maneira mais dinâmica e motivadora (MARCO; MOURA; MISKULIN, 2007, p. 3)

Fonte: Santos (2021, p.143).

Os JD, na perspectiva dos aspectos didático-metodológicos, abrem possibilidade de "detectar os alunos que estão com problemas reais" (Pontes, Bezerra \& Bandeira, 2010, p. 4). Os autores complementam:

Deve-se formar a consciência de que os sujeitos, ao aprenderem, não o fazem como puros assimiladores de conhecimentos, mas que, nesse processo, existem determinados componentes internos que não podem deixar de ser ignorados pelos educadores. (Pontes, Bezerra \& Bandeira, 2010, p. 4).

Trabalhar com jogo em sala de aula carrega vantagens para o ensino, mas alguns cuidados precisam ser tomados pelo professor antes dessa utilização. Pensando nisso, Pontes, Bezerra e Bandeira (2010) trilham caminhos em que se destacam algumas vantagens e cuidados (Quadro 3) que podem subsidiar o trabalho do professor alfabetizador matemático na utilização dos JD.

Quadro 3 - Vantagens e cuidados que podem subsidiar o trabalho do professor alfabetizador matemático na utilização dos JD

\begin{tabular}{|l|l|}
\hline \multicolumn{1}{|c|}{ Vantagens } & \multicolumn{1}{c|}{ Cuidados } \\
\hline $\begin{array}{l}\text { O aluno demonstra para seus } \\
\text { colegas e professores se o } \\
\text { assunto foi bem assimilado }\end{array}$ & $\begin{array}{l}\text { Não tornar o jogo algo } \\
\text { obrigatório }\end{array}$ \\
\hline $\begin{array}{l}\text { Existe uma competição entre } \\
\text { os jogadores e os adversários, } \\
\text { pois todos desejam vencer } \\
\text { e por isso aperfeiçoam-se e } \\
\text { ultrapassam seus limites }\end{array}$ & $\begin{array}{l}\text { Escolher jogos em que o fator } \\
\text { sorte não interfira nas jogadas, } \\
\text { permitindo que vença aquele } \\
\text { que descobrir as melhores } \\
\text { estratégias }\end{array}$ \\
\hline $\begin{array}{l}\text { Durante o desenrolar de um } \\
\text { jogo, observa-se que o aluno } \\
\text { se torna mais crítico, alerta e } \\
\text { confiante, expressando o que } \\
\text { pensa, elaborando perguntas } \\
\text { e tirando conclusões, sem } \\
\text { necessidade da interferência } \\
\text { ou aprovação do professor }\end{array}$ & $\begin{array}{l}\text { Utilizar atividades que } \\
\text { envolvam dois ou mais alunos, } \\
\text { para oportunizar a interação } \\
\text { social. }\end{array}$ \\
\hline $\begin{array}{l}\text { Não existe o medo de errar, } \\
\text { pois o erro é considerado um } \\
\text { degrau necessário para se } \\
\text { chegar a uma resposta correta }\end{array}$ & $\begin{array}{l}\text { Estabelecer regras, que podem } \\
\text { ou não ser modificadas no } \\
\text { decorrer de uma rodada }\end{array}$ \\
\hline $\begin{array}{l}\text { O aluno se empolga com o } \\
\text { clima de uma aula diferente, o o } \\
\text { que faz com que aprenda sem } \\
\text { perceber }\end{array}$ & $\begin{array}{l}\text { Trabalhar a frustração pela } \\
\text { derrota na criança, no sentido } \\
\text { de minimizá-la }\end{array}$ \\
\hline & $\begin{array}{l}\text { Estudar o jogo antes de } \\
\text { aplicá-lo (o que só é possível, } \\
\text { jogando) }\end{array}$ \\
\hline
\end{tabular}

Fonte: Adaptado de Pontes et al. (2010) 
Para Marco, Moura e Miskulin (2007), no jogo, há um enriquecimento de possibilidades para favorecer a verificação de hipóteses e conjecturas levantadas pelos alunos de maneira mais dinâmica e motivadora. Desse modo,

O jogo no ensino de matemática pode ser desencadeador de aprendizagens conceituais. Nossa suposição é de que o jogo computacional apresente e intensifique essa qualidade didática do jogo. Porém, é necessário haver a reflexão sobre seu aspecto pedagógico. Uma forma de valorizar esse aspecto é o professor fazer com que, após ter realizado o jogo ou ao realizá-lo, o aluno reflita sobre suas estratégias e tome consciência deste, buscando novos processos e investigando os conceitos envolvidos (Marco, Moura \& Miskulin, 2007, p.2).

O ensino com jogos é tema bastante presente no contexto educacional dos Anos Iniciais e, como possibilidade de aprendizagem, é gerador de um "potencial considerável no exercício de desenvolvimento das funções cognitivas" (Silva \& Scheffer, 2016, p. 3). Em aulas de matemática, o jogo digital possibilita o

[...] raciocínio lógico, a construção e fixação de conceitos, desenvolvimentos de estratégias, permite a concepção da primeira noção de sociedade no período infantil, permite um aprendizado mais prazeroso e eficaz das estruturas dos conteúdos que utilizam essa ferramenta (Alves \& Lemos, 2016, p. 2).

Nesse sentido, o "professor tem um papel fundamental: ele será o responsável pela criação e manutenção de um ambiente matemático motivador e estimulante para que a aula aconteça" (Pacto Nacional pela Alfabetização na Idade Certa, 2015, p.19).

No desembaraço dessas compreensões, alguns autores destacam aspectos relevantes, advindo de uma aula com jogos, que vem ao encontro dos três momentos citados:

Figura 5 - Encontro de fala dos autores estudados

[...] evolução da criança, incluído as atividades realizadas fora do espaço da
sala de aula e do contexto escolar (VIANA; SOUSA, 2013, p. 10).
[...] despertar grande interesse, pois fazem parte do cotidiano das crianças,
como também, conjeturam-se na atualidade como um recurso pedagógico
(FERNANDES; PINHEIRO; SANTOS JUNIOR, 2013, p. 10).
[...] atitude coletiva com a comunidade escolar, numa postura constante de
ação/reflexão/ação, assim como incentivá-los a uma discussão em classe
sobre os problemas que envolvem quantidades ou formas, estimular os
alunos a uma reflexão sobre as propostas apresentadas pelo professor
(ALMEIDA; BARBOSA, 2010, p. 3).
[...] a aprendizagem de forma natural e espontânea, pois pode trazer consigo
desafios que impulsionam na busca de conhecimentos, além de favorecer o
envolvimento social entre as crianças e a formação de outros conceitos
(SCHELLER et al, 2015, p. 126).

Fonte: Santos (2021, p.146).

O sentido que aparece nas falas dos autores nos leva a pensar no jogo digital como um artefato tecnológico que possibilita despertar o interesse do aluno. Deste modo, diversão, recompensa, risco do desafio, consistência, justiça e interesse se firmam como base no envolvimento aluno-jogodigital.

O jogo precisa despertar o interesse para movimentar o conhecimento matemático. Mas de que maneira? Se o jogo não for do interesse do aluno, ele não se envolve, não adianta ter um conteúdo explícito se o aluno não estiver interessado. O professor pode atuar reelaborando os trajetos e levando em consideração os conhecimentos que estão sendo produzidos, de modo a mobilizar o conhecimento matemático. Mas, para isso, é preciso estabelecer interrogações problematizadoras que levem o professor, a partir delas, a enxergar a essência de despertar o interesse. É preciso que saibamos quem são nossos alunos para que reflitamos sobre o que possa vir a interessá-los. Assim, quais interesses eu quero despertar em meus alunos? Quem são meus alunos? Com o que estão familiarizados?

Os jogos digitais entram nas salas de aulas com uma roupagem de ineditismo, pela especificidade (novidade) do digital (ambientes quase reais, em 3D, e muito mais imersivos pela experiência que proporciona), e pela motivação (quase sempre) que eles desenvolvem nos seus usuários (Sousa, 2015, p. 15).

O ineditismo, o novo, as experiências e a motivação nos levam a pensar sobre o que, dentro do jogo, pode proporcionar esse envolvimento. No entanto, quais desafios matemáticos são dispostos nos níveis do jogo? Esses desafios podem instigar os estudantes? Em algum momento deixa de ser desafiador perdendo a graça do jogo? O jogo pode vir com uma infinidade de conteúdos matemáticos, mas é o professor, na mediação-de-uma-aula-com-jogos-digitais, que abre possibilidades para que esses conteúdos sejam contemplados em sala de aula.

A criança se interessa por tarefas desafiantes. Para que isso ocorra, nós, professores, precisamos criar tarefas ou situações-problema de tal forma que a solução não possa ser obtida rapidamente, por meio de uma conta. Será necessário envolver a criança de modo que ela se sinta desafiada a descobrir o que precisaria fazer quando a proposta é aberta (Pacto Nacional pela Alfabetização na Idade Certa, 2015, p. 17).

Pensando nos olhares destacados nas discussões até aqui, apresentamos a seguir (Quadro 4) alguns aspectos importantes para a utilização do jogo digital em sala de aula trazidos por Marco et al (2007). São aspectos que carregam a postura do professor frente ao movimento aluno-professoraprendizagem-matemática. Para expressar a ideia dos autores, construímos um quadro que apresenta os aspectos, objetivos e descrições dessa utilização.

Quadro 4 - Aspectos importantes para a utilização do jogo digital em sala de aula

\begin{tabular}{|c|c|l|}
\hline Aspecto & Objetivo & \multicolumn{1}{c|}{ Descrição } \\
\hline & & $\begin{array}{l}\text { É importante que o professor } \\
\text { tenha contato prévio com o } \\
\text { software o explore criando } \\
\text { simulações possíveis, para que no } \\
\text { momento de utilização do mesmo } \\
\text { com os alunos, tenha condições de } \\
\text { fazer intervenções que o levem a } \\
\text { atingir os objetivos traçados }\end{array}$ \\
$\begin{array}{c}\text { Explorar } \\
\text { o software }\end{array}$ & $\begin{array}{c}\text { Conhecêterionente } \\
\text { lo }\end{array}$ & \\
\hline
\end{tabular}




\begin{tabular}{|c|c|c|}
\hline Aspecto & Objetivo & Descrição \\
\hline & $\begin{array}{l}\text { Explorá- } \\
\text { los em } \\
\text { aula }\end{array}$ & $\begin{array}{l}\text { Os jogos têm suas vantagens } \\
\text { no ensino da Matemática desde } \\
\text { que o professor tenha objetivos } \\
\text { claros do que pretende atingir } \\
\text { com a atividade proposta. Não } \\
\text { concordamos com o fato de que } \\
\text { o jogo, propiciando simulação } \\
\text { de problemas, exija soluções } \\
\text { imediatas, como defendem os } \\
\text { PCN's (1998). Entendemos } \\
\text { que as situações vivenciadas } \\
\text { durante as partidas levam o } \\
\text { jogador a planejar as próximas } \\
\text { jogadas visando um melhor } \\
\text { aproveitamento e até mesmo } \\
\text { ganhar a partida. Vale lembrar que } \\
\text { esse fato só ocorrerá se houver } \\
\text { intervenções pedagógicas por } \\
\text { parte do professor }\end{array}$ \\
\hline $\begin{array}{l}\text { Planejar as } \\
\text { atividades }\end{array}$ & $\begin{array}{l}\text { Lançar } \\
\text { propostas } \\
\text { aos alunos }\end{array}$ & $\begin{array}{l}\text { Nesta fase, é imprescindível o } \\
\text { professor planejar as atividades } \\
\text { a serem propostas aos alunos } \\
\text { no momento da aula, pois } \\
\text { somente assim conseguirá } \\
\text { oferecer situações nas quais os } \\
\text { alunos pensem e reflitam sobre } \\
\text { o que estão fazendo, discutam } \\
\text { e (re)signifiquem conceitos } \\
\text { matemáticos que estiverem sendo } \\
\text { abordados }\end{array}$ \\
\hline
\end{tabular}

Fonte: Adaptado de Marco, Moura e Miskulin (2007).

Para a utilização do jogo digital em sala de aula é necessário ater-se a aspectos técnicos e pedagógicos, tanto para com a aula, quanto para com o jogo escolhido. Dentro estes, conduzimos o olhar: ao explorar o software anteriormente com objetivo de conhecê-lo (o que subsidia a ação do professor a todo material a ser utilizado em sala de aula, no caso dos $\mathrm{JD}$, a análise técnica e pedagógica); ao traçar objetivos e explorá-los em aula (planejamento do professor para o que deseja ensinar de conteúdo); e ao planejar as atividades com objetivo de lançar propostas aos alunos (planejamento de como, posteriormente ao jogo, pode ser lançado atividades que revisitem os conhecimentos adquiridos nas jogadas para favorecer um ensino que faça sentido).

Nesse sentido, ao utilizar tais recursos é importante "conhecer e se familiarizar com a tecnologia, fazer análise cuidadosa e criteriosa do material a ser utilizado, tendo em vista os objetivos que se quer alcançar, ou seja, princípios teórico-metodológicos claros e bem fundamentados" (Tarouco et al., 2004, p. 2). O autor expressa o cuidado do professor para com os recursos tecnológicos a serem utilizados, pois não basta somente querer usar, é preciso querer aprender a usar. É o olhar para o que está em jogo no jogo.

Essas condições abrem para questões como: $\mathrm{O}$ jogo digital possui metas a serem exploradas? Quais? As ações desempenhadas durante as jogadas favorecem as jogadas seguintes? Ao errar, o jogo digital apresenta o feedback do erro? Se apresenta, faz com que o jogador reconheça seu erro e reconstrua o conhecimento para uma nova jogada? O jogo digital apresenta, de alguma forma, os conteúdos matemáticos já ensinados em sala de aula em novos contextos? O jogo possibilita, em conjunto, uma contextualização dos resultados ao final da partida? Essas orientações pedagógicas formam a estrutura de uma das interrogações que movimentaram as discussões nesta CA, a qual se mostra na Figura 6:

Figura 6 - Orientações pedagógicas para análise de JD

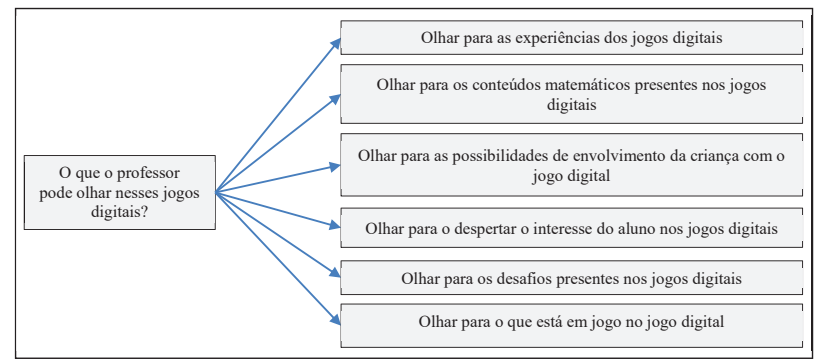

Fonte: Santos (2021, p.149).

De modo a organizar as orientações pedagógicas, o quadro a seguir (Quadro 4) mostrará a estrutura que contempla: os critérios técnicos (por meio de etapas) abordados por Marco et al. (2007); as orientações pedagógicas (por meio de olhares); e as descrições, as quais julgamos importantes para o entendimento da estrutura desenvolvida. Todos os critérios e orientações pedagógicas estão encaminhados por perguntas que se dirigem às propostas, as quais objetivam mostrar um roteiro para o professor como um modo de olhar para os JD. As descrições que remetem a essas etapas também foram conduzidas de modo a subsidiar o olhar do professor para uma aula-com-jogos-digitais.

Quadro 5 - Critérios técnicos e orientações pedagógicas para análise de JD na AM

\begin{tabular}{|c|c|l|}
\hline $\begin{array}{c}\text { Critérios e orientações } \\
\text { para auxiliar o professor na } \\
\text { utilização de JD em sala de aula }\end{array}$ & $\begin{array}{c}\text { Etapas e } \\
\text { Olhares }\end{array}$ & Perguntas que movimentam a estrutura dos critérios e orientações \\
\hline \multirow{5}{*}{ Critérios técnicos } & $\begin{array}{c}\text { Explorar } \\
\text { o software } \\
\text { anteriormente }\end{array}$ & $\begin{array}{l}\text { A interface do jogo apresenta boa legibilidade e interatividade? O layout do jogo } \\
\text { desperta interesse e/ou curiosidade? As cores, desenhos e formas do jogo chamam } \\
\text { atenção para o lúdico na criança? }\end{array}$ \\
\cline { 2 - 4 } & $\begin{array}{c}\text { Traçar } \\
\text { objetivos }\end{array}$ & $\begin{array}{l}\text { Que conteúdo é pretendido trabalhar? Como pretendo trabalhar esses conteúdos? } \\
\text { Quais perguntas e/ou conversas dirigidas podem desencadear a aprendizagem dos } \\
\text { alunos enquanto jogam? }\end{array}$ \\
\cline { 2 - 4 } & $\begin{array}{c}\text { Planejar as } \\
\text { atividades }\end{array}$ & $\begin{array}{l}\text { O jogo digital vai ser trabalhado de que maneira? Como atividade introdutória de } \\
\text { algum conteúdo? Como ação recreativa? Como atividade de observação? }\end{array}$ \\
\hline
\end{tabular}




\begin{tabular}{|c|c|c|}
\hline $\begin{array}{c}\text { Critérios e orientações } \\
\text { para auxiliar o professor na } \\
\text { utilização de JD em sala de aula }\end{array}$ & $\begin{array}{l}\text { Etapas e } \\
\text { Olhares }\end{array}$ & Perguntas que movimentam a estrutura dos critérios e orientações \\
\hline \multirow{6}{*}{ Orientações pedagógicas } & $\begin{array}{l}\text { Olhar para as } \\
\text { experiências } \\
\text { dos jogos } \\
\text { digitais }\end{array}$ & $\begin{array}{l}\text { Que aspectos presentes na estrutura do jogo, em seu enredo e contexto, estão } \\
\text { voltadas às experiências vividas pelos alunos, tanto dentro quanto fora da sala de } \\
\text { aula? O aluno, em movimento nas jogadas, conseguirá se enxergar personagem } \\
\text { do jogo digital? }\end{array}$ \\
\hline & $\begin{array}{c}\text { Olhar para } \\
\text { os conteúdos } \\
\text { matemáticos } \\
\text { presentes nos } \\
\text { jogos digitais }\end{array}$ & $\begin{array}{l}\text { Que conteúdos matemáticos podem ser explorados no jogo? Estes conteúdos } \\
\text { estão sendo atrelados ao nível de aula planejada? Como ministrar uma aula que } \\
\text { contemple esses conteúdos? }\end{array}$ \\
\hline & $\begin{array}{l}\text { Olhar para as } \\
\text { possibilidades } \\
\text { de } \\
\text { envolvimento } \\
\text { da criança } \\
\text { com os jogos } \\
\text { digitais }\end{array}$ & $\begin{array}{l}\text { Que estruturas/etapas e/ou movimentos o jogo digital possui que possibilitem o } \\
\text { envolvimento da criança enquanto joga? Como mediar a utilização desse jogo } \\
\text { digital para que haja envolvimento? }\end{array}$ \\
\hline & $\begin{array}{c}\text { Olhar para o } \\
\text { despertar do } \\
\text { interesse do } \\
\text { aluno pelos } \\
\text { jogos digitais }\end{array}$ & $\begin{array}{l}\text { Quais interesses eu quero despertar em meus alunos? Quem são meus alunos? } \\
\text { Com o que estão familiarizados? }\end{array}$ \\
\hline & $\begin{array}{l}\text { Olhar para } \\
\text { os desafios } \\
\text { presentes nos } \\
\text { jogos digitais }\end{array}$ & $\begin{array}{l}\text { Quais desafios matemáticos são dispostos nos níveis do jogo? Estes desafios } \\
\text { podem instigar os estudantes? Em algum momento deixa de ser desafiador } \\
\text { perdendo a graça do jogo? }\end{array}$ \\
\hline & $\begin{array}{l}\text { Olhar para } \\
\text { o que está } \\
\text { em jogo nos } \\
\text { jogos digitais }\end{array}$ & $\begin{array}{l}\text { O jogo digital possui metas a serem exploradas? Quais? As ações desempenhadas } \\
\text { durante as jogadas favorecem as jogadas seguintes? Ao errar, o jogo digital } \\
\text { apresenta o feedback do erro? Se apresenta, faz com que o jogador reconheça seu } \\
\text { erro e reconstrua o conhecimento para uma nova jogada? O jogo digital apresenta, } \\
\text { de alguma forma, os conteúdos matemáticos já ensinados em sala de aula em } \\
\text { novos contextos? O jogo possibilita, em conjunto, uma contextualização dos } \\
\text { resultados ao fim da partida? }\end{array}$ \\
\hline
\end{tabular}

Fonte: Adaptado de Santos (2021).

\section{Síntese do Estudo}

Ao longo do estudo definimos AM como o ato de aprender a ler e a escrever em linguagem Matemática, isto é, compreender e interpretar os sinais, signos e símbolos que expressam ideias matemáticas que sustentam compreensões e leituras do mundo. Destacamos ainda que em meio aos avanços da $\mathrm{TD}$, a formação de professores não pode se restringir apenas aos temas discutidos em sua formação inicial. Em relação ao ensino de Matemática, destacamos que o desenvolvimento da área de Educação Matemática no país, com a abundância de congressos e textos, ampliou consideravelmente a produção de conhecimentos sobre o ensino desta disciplina. No entanto, este conhecimento produzido nem sempre está presente nas formações iniciais dos professores.

Também concordamos com os estudos que apontam que há, para os professores, demandas profissionais que exigem uma contínua atualização, de modo a aprofundar conhecimentos teóricos, sintonizando as reformas curriculares, com distintos métodos de ensino, tecnologias e recursos materiais que contribuam para a eficácia do trabalho docente.

Os aspectos didático-metodológicos se guiaram nesta pesquisa por compreensões acerca do professor alfabetizador e da utilização de JD em sala de aula num processo que envolve o fenômeno jogos-digitais-na-alfabetização-matemática.
O olhar para despertar o interesse do aluno nos JD, para os desafios dos JD e para o que está em jogo foram as orientações que se mostram em meio as discussões deste trabalho. Entendemos que o processo de AM frente à utilização de JD é um caminho possível, favorável e desvelador. No entanto, carece de um cuidado pedagógico do professor para com o JD e seu planejamento quanto à aplicação em sala de aula. Nesse sentido, perguntamos: que subsídios para o professor alfabetizador matemático vem se mostrando nos trabalhos analisados? Os trabalhos apresentam a necessidade de saber olhar esses jogos, analisando suas experiências e sua aplicação para os conteúdos matemáticos presentes. Apontam para as possibilidades de envolvimento da criança, para o despertar do interesse do aluno, para os desafios presentes e para o que está em jogo no jogo.

A preocupação inicial para essa proposta foi com o professor que não é habituado aos meios tecnológicos digitais, no sentido de olhar os JD e traçar um roteiro para sua aplicação. Portanto, os critérios apontados e adaptados e as orientações pedagógicas destacadas no Quadro 5 foram desenvolvidos para subsidiar o professor na seleção e análise de JD para aplicação em sala de aula.

Optar por fazer as análises nas produções acadêmicas, que tematizam jogos e JD em sala de aula, foi uma busca por saber 
o que a academia vem dizendo sobre essa utilização e o que dela poderíamos destacar para dar subsídios aos professores no processo de AM. Foi uma busca por orientações para auxiliar o professor a lançar mãos desses jogos, apresentando caminhos que reduzem o trajeto de busca, apontando endereçamentos da utilização dos JD ao professor.

\section{Referencias}

Amado, N. M. P., \& Carreira, S. P. G. (2015) Recursos tecnológicos no ensino e aprendizagem matemática. In: Dullius, M. M. \& Quartieri, M. T (Org.). Explorando a Matemática com aplicativos computacionais: anos iniciais do ensino fundamental (pp. 9-18). Lajeado: Editora da Univates.

Pacto Nacional pela Alfabetização na Idade Certa. (2015). Dispõe sobre a Alfabetização matemática na perspectiva do letramento. Caderno 07/Ministério da Educação, Secretaria de Educação Básica, Diretoria de Apoio à Gestão Educacional. Brasília: MEC.

Balbino, R. O. (2015). Os objetos de aprendizagem de matemática do PNLD 2014: uma análise segundo as visões construtivista e ergonômica. Dissertação de Mestrado da Universidade Federal do Paraná, Curitiba, PR, Brasil. Disponível: https:// acervodigital.ufpr.br/handle/1884/44080

Danyluk, O. S. (2010). As relações da criança com a alfabetização matemática. In: Baumann, A. P. P., Miarka, R.; Mondini, F., Lammoglia, B. \& Borba, M. C. (Org.). Maria em Forma/ Ação (pp. 28 - 33). Rio Claro: Editora IGCE.

Gadamer, H. (1999). Verdade e método: Traços fundamentais de uma hermenêutica filosófica. Petrópolis: Vozes.

Garnica, A. V. M. (1997). Algumas notas sobre pesquisa qualitativa e fenomenologia. Interface Comunicação, Saúde, Educação, 1(1).
Huizinga, J. (2019). Homo Ludens [recurso eletrônico]: o jogo como elemento da cultura. São Paulo: Perspectiva,

Merleau-ponty, M. (1984). Sobre a fenomenologia da linguagem (M. S. Chauí, (Trad.). In M. S. Chauí (Org.). Maurice Merleau-Ponty: textos selecionados (pp.129-140). São Paulo: Abril Cultural.

Marco, F. F., Moura, A. R. L., Miskulin, R. G. S. (2007, julho) Jogos computacionais em aulas de matemática: uma perspectiva para a resolução de problemas. Anais do Encontro Nacional de Educação Matemática, Belo Horizonte, MG, Brasil, IX.

Pontes, A. C. F., Bezerra S. M. C. B., Bandeira, S. M. C. (2010, julho) Metodologias alternativas no ensino da matemática: jogos e oficinas pedagógicas. Anais do Encontro Nacional de Educação Matemática, Salvador, BA, Brasil, X.

Prensky, Marc. (2012). Aprendizagem baseada em jogos digitais. São Paulo: Senac São Paulo.

Silva, S. L. D., Scheffer, N. F. (2016). Os jogos digitais online na educação matemática: apontamentos da neurociência cognitiva. Anais do Encontro Nacional de Educação Matemática, São Paulo, SP, Brasil, XII.

Salen, K., Zimmerman, E. (2004). Rules of Play: Game Design Fundamentals. Londres: The MIT Press.

Sousa, C. A. B. (2015) O jogo em jogo: a contribuição dos games no processo de aprendizagem de estudantes do ensino fundamental. Dissertação de mestrado, Universidade Federal de Pernambuco, Recife, PE, Brasil.

Santos, D. S. S. (2021). Jogo digital na alfabetização matemática: contribuição para caminhos didático-metodológicos Dissertação de mestrado, Universidade Tecnológica Federal do Paraná, Paraná, PR, Brasil.

Tarouco, L. M. R. (2004) Jogos educacionais. Revista Novas Tecnologias na Educação, 2(1). 